\title{
Tribological characterization of tungsten nitride coatings deposited by reactive magnetron sputtering
}

\author{
T. Polcar, N.M.G. Parreira, A. Cavaleiro* \\ ICEMS - Grupo de Materials e Engenharia de Superficies, Faculdade de Ciências e Tecnologia da \\ Universidade de Coimbra - Pólo II, 3030-788 Coimbra, Portugal
}

Received 15 April 2006; received in revised form 6 July 2006; accepted 20 July 2006

Available online 23 August 2006

\begin{abstract}
The structure, hardness, friction and wear of tungsten nitrides prepared by d.c. reactive magnetron sputtering were investigated. The coatings were deposited with different nitrogen to argon ratios; the total pressure was kept constant. The tribological tests were performed on a pin-on-disc tribometer in terrestrial atmosphere with $100 \mathrm{Cr} 6$ steel, $\mathrm{Al}_{2} \mathrm{O}_{3}$ and $\mathrm{Si}_{3} \mathrm{~N}_{4}$ balls as sliding counter-bodies. The wear tracks, the ball-wear scars and the wear debris were analysed by scanning electron microscopy in order to characterize the dominant wear mechanisms.

The coatings exhibited different phases as a function of the nitrogen content: films with low $\mathrm{N}$ content exhibited the $\alpha-\mathrm{W}$ phase; $\beta$-W phase was dominant for nitrogen contents from 12 to 15 at. $\%$ and $\beta-\mathrm{W}_{2} \mathrm{~N}$ was observed for nitrogen content higher that 30 at. $\%$. The mechanical and tribological properties of the tungsten nitride coatings were strongly influenced by the structure. The hardness and the Young's modulus values were in the ranges (29-39 GPa) and (300-390 GPa), respectively; the lowest values correspond to the coatings with the highest nitrogen content. Generally, the friction and wear rate of tungsten nitride coatings sliding against ceramic balls increased with nitrogen content reaching a maximum at 12 at.\%; further increase of the nitrogen content led to a decrease of the friction and wear. The sliding with the steel balls did not wear the coatings under the selected testing conditions.
\end{abstract}

(c) 2006 Elsevier B.V. All rights reserved.

Keywords: Unlubricated friction; Friction mechanisms; Nitrides; Tungsten; Coatings; Wear-resistant

\section{Introduction}

Transition metal nitrides are known for the unique combination of excellent mechanical properties (hardness and Young's modulus), high melting point, good chemical stability and high conductivity [1]. However, tungsten nitrides still stand aside of the main attention, particularly compared to titanium or chromium nitrides. The first studies of tungsten nitride thin films deposited by magnetron sputtering were focused mainly on the deposition process and structural properties [2]; further studies were performed, basically, for electronic applications such as, diffusion barriers [3] or semiconductors [4]. In the 90s, W-N coatings were started to be studied for mechanical applications [5] and further studies were performed on the addition of different elements (e.g. W-Ti-N [6] and $\mathrm{W}-\mathrm{Si}-\mathrm{N}[7]$ ) in order to improve the mechanical properties of the coatings. In con-

\footnotetext{
* Corresponding author.

E-mail address: albano.cavaleiro@dem.uc.pt (A. Cavaleiro).
}

trast to thoroughly studied composition and structural properties $[8,9,10]$, there are only few studies dealing with the tribological properties of tungsten nitrides that could show their good wear resistance [5]. Moreover, this study only dealt with coatings with very low nitrogen content.

The present study is focused on the tribological behaviour (friction coefficient and wear rate) of tungsten nitride coatings prepared with different nitrogen content in a large range from 5 to 55 at. $\%$.

\section{Experimental details}

Tungsten nitride coatings were deposited by d.c. reactive magnetron sputtering from a tungsten target. Pure argon and nitrogen were used as sputtering and reactive gases, respectively. High speed steel, AISI M2, substrates (chemical composition: C 0.86, $\mathrm{Si}<0.40, \mathrm{Mn}<0.40, \mathrm{Cr} 4.20$, Mo 5.00, V 1.90, W 6.40) were thermally treated prior to the deposition to reach a final hardness close to $9 \mathrm{GPa}$. The substrates were mirror polished to reach a roughness $\mathrm{Ra} \leq 30 \mathrm{~nm}$. 
The deposition runs were performed taking constant the following parameters: total working pressure $(0.3 \mathrm{~Pa})$, target current density $\left(10 \mathrm{~mA} \mathrm{~cm}^{-2}\right)$, substrate at floating potential, no substrate rotation, inter-electrode distance $(65 \mathrm{~mm})$ and substrate temperature $\left(<350^{\circ} \mathrm{C}\right.$, with no external heating). Thus, the only variable for different depositions was $\mathrm{N}_{2} / \mathrm{Ar}$ ratio, which was in range from 0 , corresponding to pure tungsten, to 3 corresponding to the highest nitrogen content. Before deposition, an ultimate vacuum pressure better than $5 \times 10^{-4} \mathrm{~Pa}$ was reached and the substrates surface was ion cleaned with an ion gun following the procedure described somewhere else [11].

A Cameca SX-50 electron probe microanalysis apparatus (EPMA) was used for determining the chemical composition of the coatings. The structure of the films was analysed by X-ray diffraction (XRD) using a Philips diffractometer with $\mathrm{Co} \mathrm{K} \alpha$ radiation $(\lambda=0.178897 \mathrm{~nm})$ in Bragg-Brentano configuration. The crystallite size was determined using Scherrer's equation.

The hardness $(H)$ and Young's modulus $(E)$ of the coatings were evaluated by depth-sensing indentation technique using a Fischer Instruments-Fischerscope. The load $P$ was increased in 60 steps until the indentation load of $50 \mathrm{mN}$ was reached and the same steps were used during unloading. The testing procedure includes the correction of the experimental results for geometrical defects in the tip of the indenter, thermal drift of the equipment, and uncertainty in the initial contact; for more details see [12]. The maximum depth of indentation was about $250 \mathrm{~nm}$. The Poisson ratio used for the calculation of the Young's modulus was 0.29 . The residual stress value was determined by the deflection method using Stoney's equation [13] through the substrate curvature radii, both before and after coating deposition [14].

The adhesion/cohesion of the coatings was evaluated by scratch-testing technique using a Revetest, CSM Instruments. The load was increased linearly from 0 to $50 \mathrm{~N}$ (Rockwell C $200 \mu \mathrm{m}$ radius indenter tip, loading speed of $100 \mathrm{~N} / \mathrm{min}$, and scratch speed of $10 \mathrm{~mm} / \mathrm{min}$ ). The $L_{\mathrm{c}}$ values corresponding to the different failure mechanisms (adhesive/cohesive) were measured by analyzing the failures events in the scratch track by optical and scanning electron microscopy.

Wear testing was done using a pin-on-disc tribometer (CSM Instruments). Three different materials were used as counterparts: $100 \mathrm{Cr} 6$ bearing steel, $\mathrm{Si}_{3} \mathrm{~N}_{4}$ (HV hardness $19 \mathrm{GPa}$ ) and $\mathrm{Al}_{2} \mathrm{O}_{3}$ balls (HV hardness $15.5 \mathrm{GPa}$ ) with a diameter of $6 \mathrm{~mm}$. The surface roughness $\mathrm{Ra}$ of the ceramic balls was lower than $15 \mathrm{~nm}$. All measurements were provided with a load of $5 \mathrm{~N}$ and a linear speed of $0.05 \mathrm{~m} / \mathrm{s}$, relative humidity of air was kept constant at $(25 \pm 5) \%$. The maximum static Hertzian pressure for an elastic contact between the ball and the coating was about $1.5 \mathrm{GPa}\left(\mathrm{Al}_{2} \mathrm{O}_{3}\right)$ and $1.25 \mathrm{GPa}\left(\mathrm{Si}_{3} \mathrm{~N}_{4}\right)$. The standard number of cycles was 5000 .

The worn volume of the balls was evaluated by optical microscopy by the following procedure: the ball wear scar was photographed three times, one in front position and two from the side (the ball was rotated about $90^{\circ}$ ). The ball wear rate was calculated from the difference between the real ball surface after the test and the projection of an ideal ball. The morphology of the coating surface, ball scars, wear tracks and wear debris were
Table 1

Coating thickness and the maximum depths of the wear tracks for sliding with $\mathrm{Al}_{2} \mathrm{O}_{3}$ (MDA) and $\mathrm{Si}_{3} \mathrm{~N}_{4}$ (MDS) balls

\begin{tabular}{llll}
\hline Nitrogen content (at.\%) & Coating thickness $(\mu \mathrm{m})$ & MDA $(\mu \mathrm{m})$ & MDS $(\mu \mathrm{m})$ \\
\hline 0 & 2.50 & 0.45 & 0.12 \\
5 & 2.33 & 0.45 & 0.15 \\
10 & 1.81 & 0.15 & - \\
12 & 2.50 & 0.59 & - \\
15 & 2.34 & 0.32 & 0.20 \\
33 & 1.85 & 0.19 & - \\
35 & 1.75 & 0.30 & - \\
42 & 1.75 & 0.34 & 0.17 \\
55 & 1.45 & 0.10 & 0.11 \\
\hline
\end{tabular}

examined by scanning electron microscopy (SEM - Philips) and the chemical analysis of the wear tracks and the wear debris was obtained by energy-dispersive X-ray analysis (EDX - EDAX). The profiles of the wear tracks were measured by mechanical profilometer. The wear rates of the ball and coating were calculated according to [15] as the worn material volume per sliding distance and normal load. The average value of five profiles measured on one wear track was used to calculate the coating wear rate.

The maximum depth of the wear track reached in the tests was only about $25 \%$ of the thickness of the coating, which should minimize the influence of the substrate on the tribological properties of the coatings, see Table 1 .

\section{Results}

\subsection{Chemical composition, structure and morphology}

The chemical composition of the deposited coatings (measured by EPMA) is shown in Fig. 1 as a function of the partial pressure of the reactive gas. Increasing the nitrogen partial pressure ratio $\left(p_{\mathrm{N} 2} / p_{\mathrm{Ar}}\right)$ from 0 to 3 led to a linear increase of the nitrogen content in the films from 0 to 55 at.\%. Also, vestiges

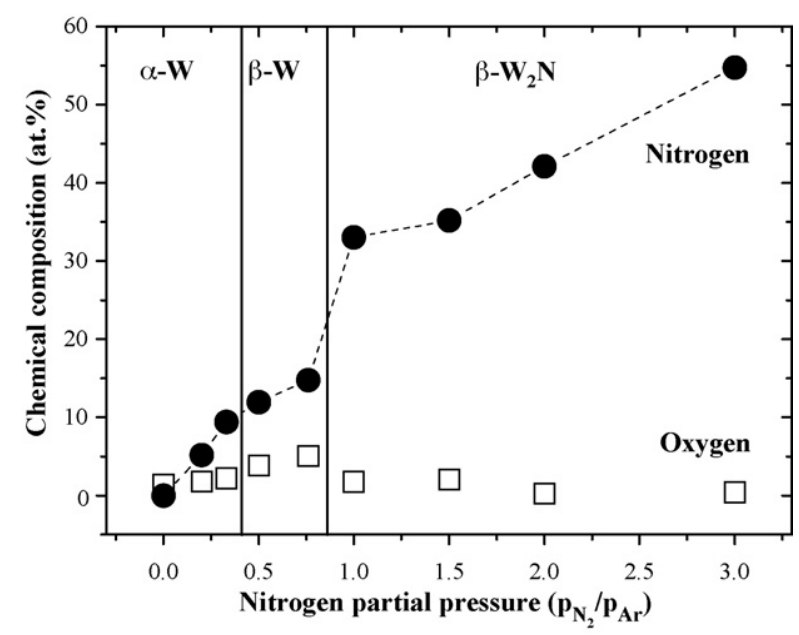

Fig. 1. Evolution of the chemical composition of $\mathrm{W}-\mathrm{N}$ coatings as a function of the nitrogen partial pressure. The figure is divided in three zones corresponding to the dominant structure of the coatings. 


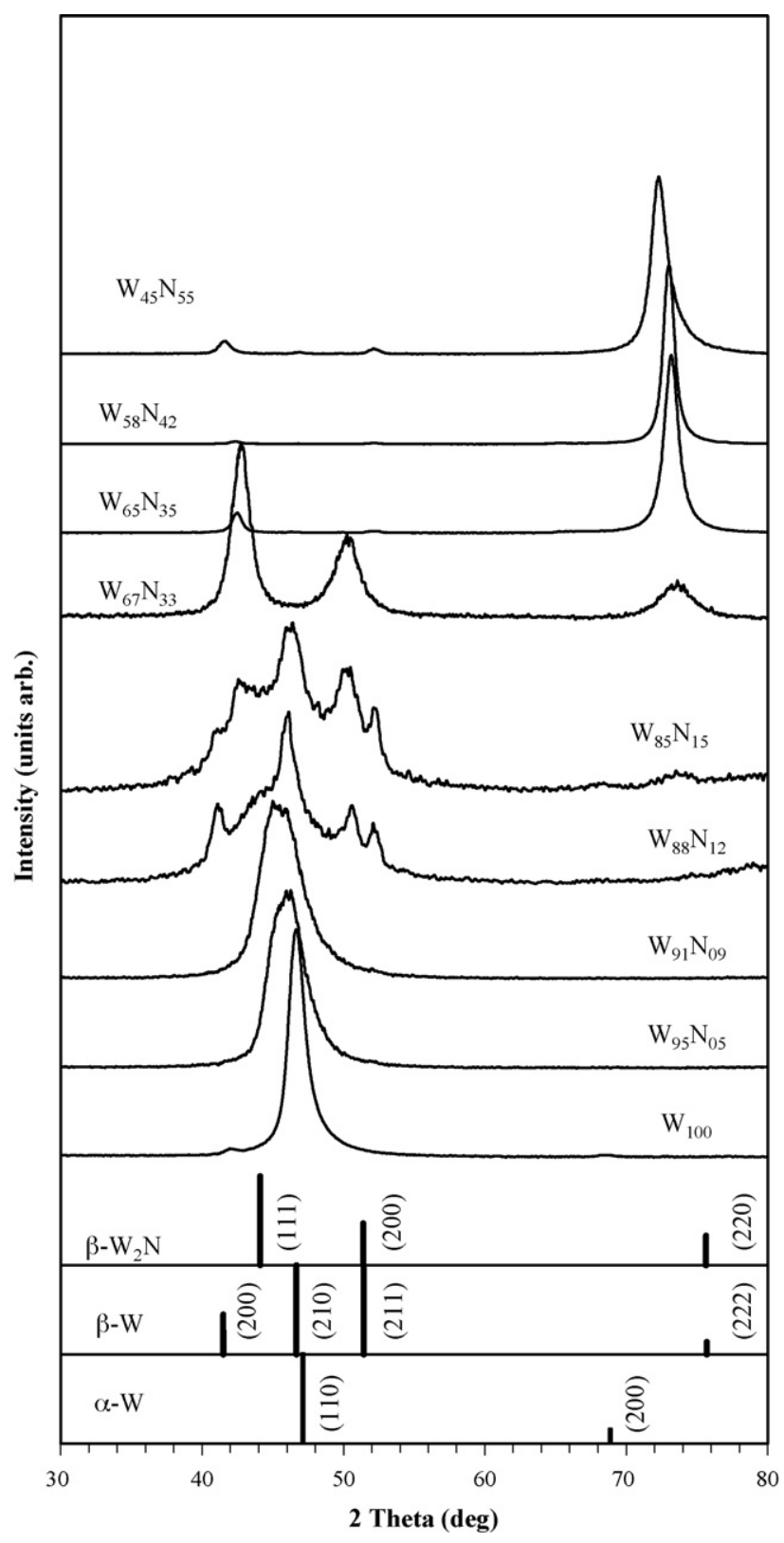

Fig. 2. XRD diffractograms of tungsten nitride coatings.

of oxygen were observed ( $<5$ at. $\%)$, principally for the coatings with low nitrogen content.

The XRD diffractograms of tungsten nitride coatings are depicted in Fig. 2. The structure of the coatings can be correlated with their chemical composition. In Fig. 1 three main zones are considered: (i) for low nitrogen content $(\mathrm{N}<9$ at.\%), the coatings exhibited a structure typical of $\alpha-\mathrm{W}$ with $\left(\begin{array}{lll}1 & 1 & 0\end{array}\right)$ preferential orientation, (ii) for coatings with intermediate nitrogen content, $\mathrm{W}_{88} \mathrm{~N}_{12}$ and $\mathrm{W}_{85} \mathrm{~N}_{15}$, the structure is a mixture of phases with the common $\beta-\mathrm{W}$ phase mixed with $\alpha-\mathrm{W}$ and $\beta-\mathrm{W}_{2} \mathrm{~N}$, respectively, (iii) for coatings with the highest nitrogen contents $(\mathrm{N}>33$ at.\%) the structure is only formed by the NaCl-type nitride compound, $\beta-\mathrm{W}_{2} \mathrm{~N}$, with (220) preferential orientation. The evolution of the chemical composition and the structure of the tungsten nitride coatings as a function of the nitrogen content have been discussed in detail in authors' previous work [11].

SEM micrographs of all coating cross-sections showed typical columnar morphology (Fig. 3).

\subsection{Hardness and residual stress}

Fig. 4 shows the evolution of the residual stress and the hardness as a function of the nitrogen content in $\mathrm{W}-\mathrm{N}$ coatings. It is interesting to observe that both results have the same trend. Thus, it is possible to establish a linear relationship between the hardness and the residual stress, showing that not only the phase formation but also the lattice distortions related to the structural defects that induce increasing intrinsic stresses are determinant effects influencing the measured hardness of the coating.

All coatings display a compressive residual stress state, resulting from the backscattered energetic neutral impinging on the growing film surface [16]. Fig. 4 shows that the residual stress is closely connected to the coating structure following the three zones mentioned in previous section. The coatings with low nitrogen content $(\mathrm{N}<9$ at.\%), exhibit a $\alpha-\mathrm{W}$ structure. The increasing nitrogen content from 0 to 9 at.\% in the coating, promotes a shift in the $\alpha-\mathrm{W}(110)$ peak position to lower diffraction angles, suggesting that nitrogen is being placed in interstitial positions in the lattice, giving rise to the dilatation of the lattice parameter and inducing increasing compressive stresses from 3.7 to $4.8 \mathrm{GPa}$. Due to this increasing of the compressive residual stress value, the hardness also increases from 22 to $40 \mathrm{GPa}$. $\beta-\mathrm{W}$ phase is dominant for coatings with intermediate nitrogen content, $\mathrm{W}_{88} \mathrm{~N}_{12}$ and $\mathrm{W}_{85} \mathrm{~N}_{15}$. This phase is known to have low compressive residual stress [17], or even tensile stress [18]. In consequence, the residual stress value of these two coatings dropped to -3.3 and $-3.4 \mathrm{GPa}$, respectively, leading to a decrease in the hardness down to values close to $29 \mathrm{GPa}$.

For high nitrogen content coatings ( $\mathrm{N} \geq 33$ at.\%), the coatings display the $\beta-\mathrm{W}_{2} \mathrm{~N}$ phase, without or with (220) preferential orientation. The hardness of these coatings decrease proportionally from 41 to $30 \mathrm{GPa}$. Such a trend can be interpreted by the synergetic effect of the compressive residual stress decrease (see Fig. 3) with the change in the preferential orientation of the films.

The evolution of the Young's modulus follows the same trend as the hardness. For hard materials with brittle fracture, as can be considered as these W-N coatings, the Griffith's theory [19] can be applied, resulting in a linear relationship between $H$ and $E$. The only case where this correlation seems not being applied is for pure $\mathrm{W}$ coating which is characterized by a strong covalent character. All coatings show $H / E$ ratio close to 0.1 , which is a promising result for tribological behaviour as it has been reported by several authors $[20,21]$.

\subsection{Adhesion}

The adhesion/cohesion of the coatings to the substrate is an important subject to consider regarding their mechanical applications. A suitable procedure to measure the adhesion/cohesion 

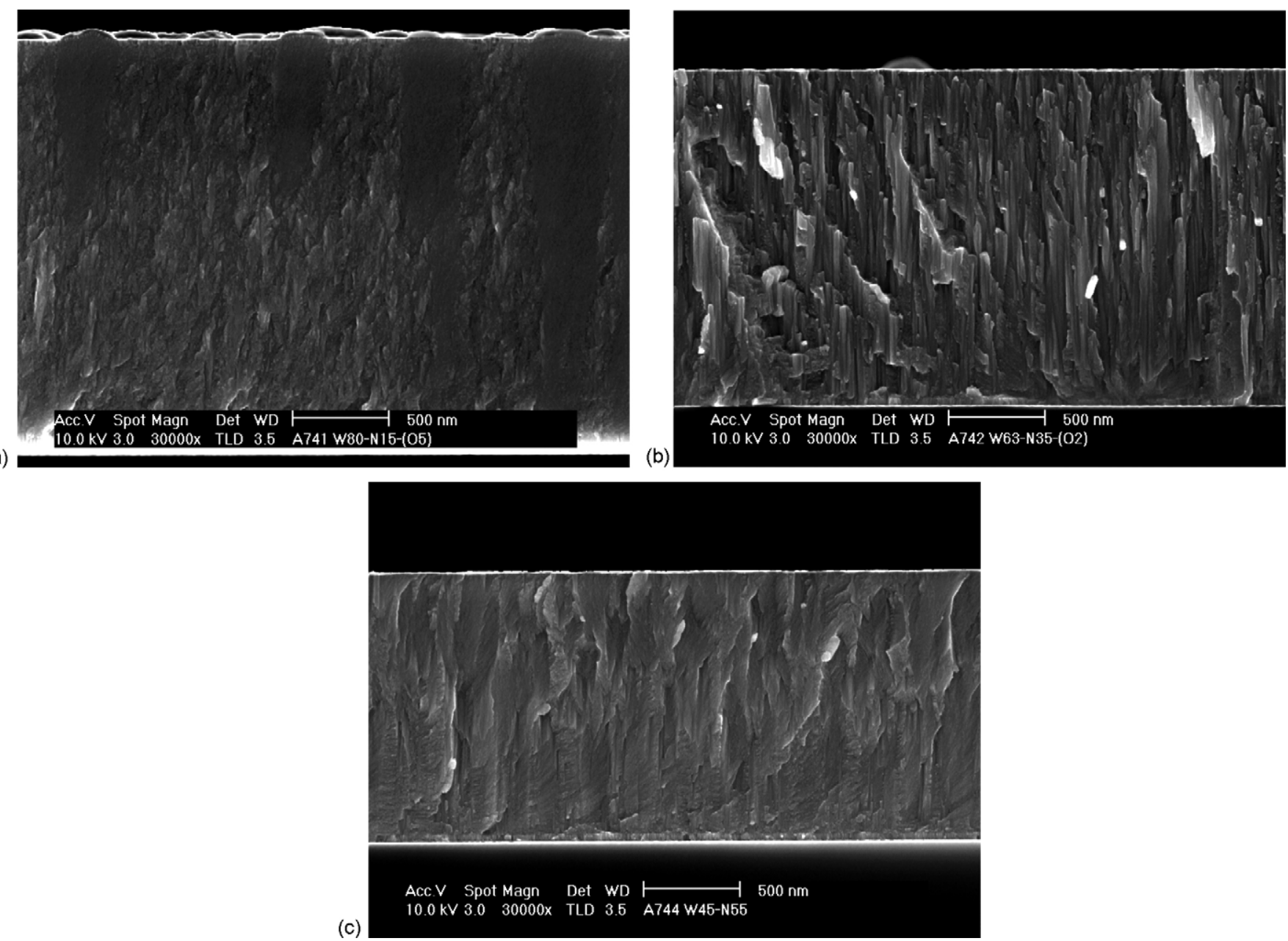

Fig. 3. SEM micrographs of the cross-section morphology of the coatings: (a) $\mathrm{W}_{85} \mathrm{~N}_{15}$, (b) $\mathrm{W}_{67} \mathrm{~N}_{33}$ and (c) $\mathrm{W}_{44} \mathrm{~N}_{55}$.

values consists of using a scratch-test apparatus to calculate the critical loads $L_{\mathrm{c} 1}$ and $L_{\mathrm{c} 2}$. These critical loads are defined as the first cohesive and adhesive failures, respectively. $L_{\mathrm{c} 1}$ and $L_{\mathrm{c} 2}$ values decreased linearly with increasing nitrogen content from 18 to $9 \mathrm{~N}$ and from more than 50 to $13 \mathrm{~N}$, respectively. Pure

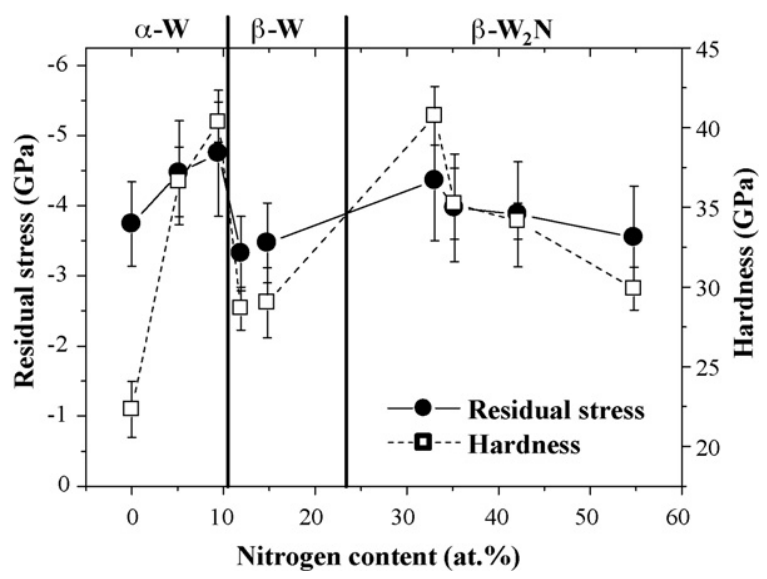

Fig. 4. Evolution of the residual stress and the hardness of W-N coatings as a function of their nitrogen content. tungsten coating exhibited $L_{\mathrm{c} 2}$ value higher than the maximum applied load (50 N).

\subsection{Tribological characterization}

\subsubsection{Friction and wear of the coatings}

The sliding against $100 \mathrm{Cr} 6$ balls did not wear W-N coatings. The materials in the contact after the running-in period are predominantly: (1) steel of the ball and (2) transferred material from the ball consisting, particularly, of iron oxides. The transferred material adheres to the coating surface impeding its wear but causing further damage to the ball. Consequently, the friction coefficient, which reached a value close to 0.8 for all nitrogen contents, cannot be considered as a parameter describing the tribological property of tungsten nitride coatings. Thus, it is possible to conclude that $100 \mathrm{Cr} 6$ balls are not applicable as a counterpart for the tribological testing performed in this study under the selected sliding conditions.

Fig. 5 shows the evolution of the friction coefficient and the coating wear rate with increasing nitrogen content in the coatings when sliding against $\mathrm{A}_{2} \mathrm{O}_{3}$ balls. In a first step, raising the nitrogen content led to increasing friction coefficient (with the exception of pure tungsten coating) reaching a maximum value 


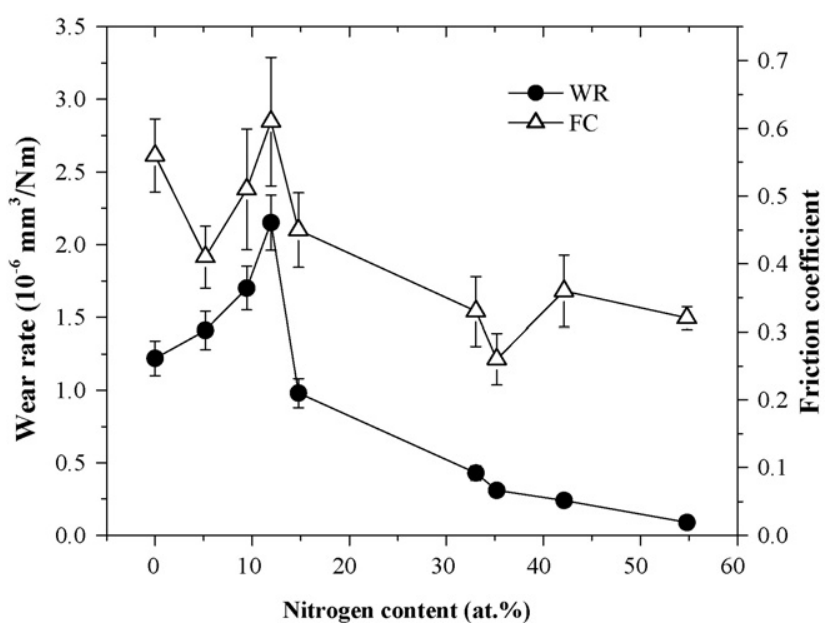

Fig. 5. Tribological properties of W-N coatings as a function of their nitrogen content (sliding against $\mathrm{Al}_{2} \mathrm{O}_{3}$ balls).

of 0.61 for 12 at. $\% \mathrm{~N}$. For higher $\mathrm{N}$ contents, the friction coefficient fell down and remained at values lower than 0.40 . The wear rate exhibited a similar behavior, again with a sharp maximum for the coating with 12 at.\% N. However, unlike friction, with further increase of $\mathrm{N}$ content, the wear rate steadily decreased, reaching the lowest value, $0.09 .10^{-6} \mathrm{~mm}^{3} / \mathrm{Nm}$, for 55 at. $\% \mathrm{~N}$. The main feature which seems to determine the inversion in the tribological behaviour of $\mathrm{W}-\mathrm{N}$ coatings is the presence of the $\mathrm{NaCl}$ type $\mathrm{W}_{2} \mathrm{~N}$ phase. In fact, the drop in the friction and wear coefficients was registered for the coating in which this phase started to be dominant.

The coatings were also tested against $\mathrm{Si}_{3} \mathrm{~N}_{4}$ balls, see Fig. 6 . In spite of the lower number of tested samples, globally a similar trend to that of $\mathrm{A}_{2} \mathrm{O}_{3}$ balls was observed for the wear rate. After a first increase of the wear rate for low $\mathrm{N}$ contents, a progressive drop is achieved for increasing $\mathrm{N}$ contents. However, the evolution of the friction coefficient is quite different. In fact, instead of the decrease in its value for the high $\mathrm{N}$ contents, the inverse is obtained. Generally, the friction coefficient is higher

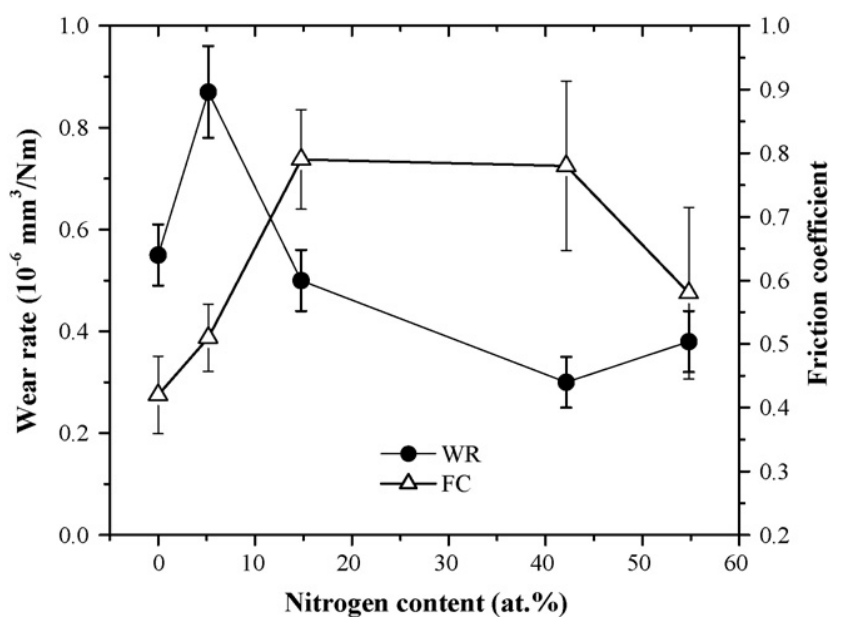

Fig. 6. Friction coefficient and wear rate of $\mathrm{W}-\mathrm{N}$ coatings when sliding against $\mathrm{Si}_{3} \mathrm{~N}_{4}$ balls.

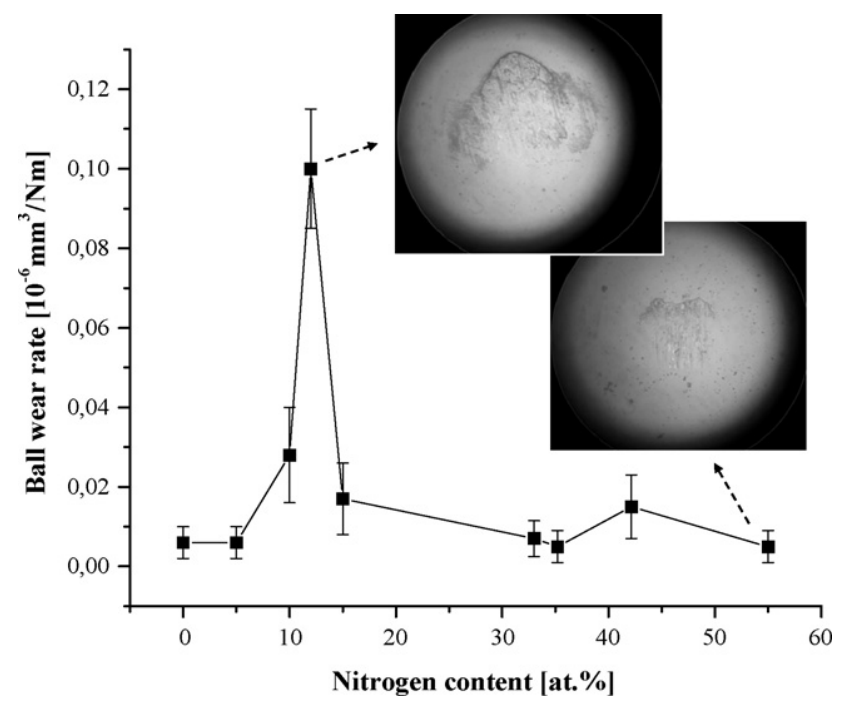

Fig. 7. Evolution of the wear rate of the $\mathrm{Al}_{2} \mathrm{O}_{3}$ ball when sliding against $\mathrm{W}-\mathrm{N}$ films with increasing $\mathrm{N}$ content. Optical micrographs of typical ball wear scars are also presented.

than that of $\mathrm{Al}_{2} \mathrm{O}_{3}$ balls whereas the wear rate is much lower for the films with low $\mathrm{N}$ content being the difference attenuated and even inversed for the highest $\mathrm{N}$ percentages.

\subsubsection{Ball wear scars}

The evaluation of the wear of $\mathrm{Al}_{2} \mathrm{O}_{3}$ balls was very difficult. In general, all ball scars were very small and transfer of coating material to the ball surface has been observed. Qualitatively all balls show the same aspect and only in the case of the one tested with $\mathrm{W}_{88} \mathrm{~N}_{12}$ film, a measurable ball scar could be detected (Fig. 7). The worn ball material volume is usually calculated as a spherical (or ellipsoidal) segment, which is worn out, but in this case the damage of the ball is made particularly by scratches on the ball surface, keeping the ball its round shape. As a consequence, the error of the calculation of the ball wear rate is relatively high.

By its side, the wear of $\mathrm{Si}_{3} \mathrm{~N}_{4}$ balls was much higher than that of alumina oxide balls (Fig. 8). In this case, the wear scar is almost an ideal spherical segment allowing the easy determination of the worn volume. The balls underwent polishing wear, since no scratches on the wear scar were visible (see micrographs in the inset of Fig. 8).

\section{Discussion}

The main factors influencing the tribological properties of coatings are the wear mechanisms and modes, which depend on a variety of different parameters. Because of the complexity of wear process, it is almost impossible to exactly describe the mechanisms of the material removal. Moreover, the observation of the worn surfaces is hindered by a large amount of adhered wear debris. Nevertheless, the detailed analysis of the tribological results can be sufficient to reveal the dominant wear mechanism and to explain the evolution of the wear rate with the nitrogen content in the films. The analysis was focused on 


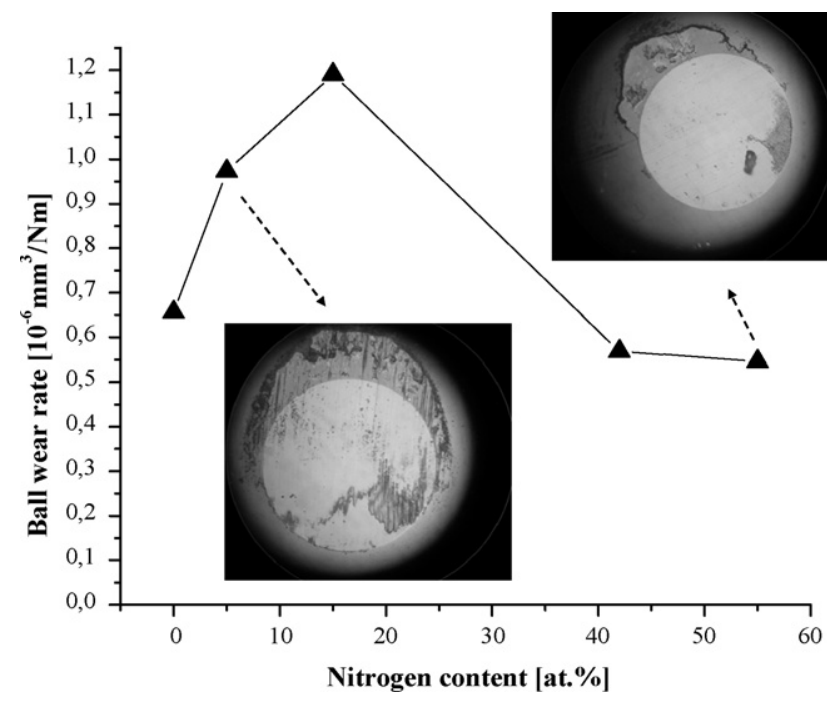

Fig. 8. Evolution of the wear rate of the $\mathrm{Si}_{3} \mathrm{~N}_{4}$ ball when sliding against $\mathrm{W}-\mathrm{N}$ films with increasing $\mathrm{N}$ content. Optical micrographs of typical ball wear scars are also presented.

the wear debris (the size, the shape and the chemical composition of wear particles) and on the wear tracks (wear track profiles, adhered wear debris, chemical analysis of the worn surface, crack analysis). These investigations were complemented taking into account the mechanical and the structural properties of the coatings.

\section{1. $W-N$ coatings with low nitrogen content sliding against $\mathrm{Al}_{2} \mathrm{O}_{3}$ balls}

The analysis of the wear particles carried out by SEM has revealed that there are two different types of wear particles: small round particles with an average dimension less than $50 \mathrm{~nm}$ and large particles with sharp edges with a grit size of $1-3 \mu \mathrm{m}$ (Fig. 9). The highest concentration of the large particles occurs

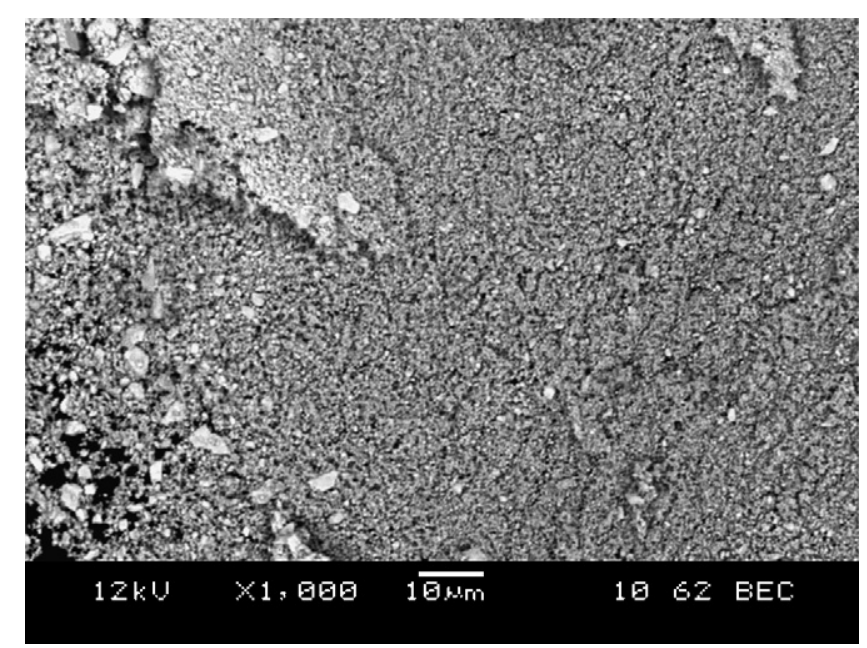

Fig. 9. SEM micrograph of the wear debris (back-scattered electrons) taken from the wear track of the coating $\mathrm{W}_{90} \mathrm{~N}_{10}$. Large tungsten-rich particles are visible (white particles), but the wear debris consists predominantly of small nanometric round tungsten trioxide particles. in the wear debris of the coating with 12 at. $\% \mathrm{~N}$; however, even in this case, the amount of the small particles is clearly dominant. It should be pointed out that the wear debris was taken from the contact area and not from the outside of the wear track. The chemical composition of the small particles measured by EDX is almost stoichiometric tungsten trioxide with no vestiges of nitrogen. The large particles are not oxidized (the amount of oxygen detected by EDX is close to the typical value of the oxide surface contamination), which is confirmed by their lighter tonality in the back-scattered SEM micrographs of the wear debris in Fig. 9.

Generally, the wear tracks are relatively deep and almost no wear debris is adhered on their central or side zones, see Fig. 10a and $\mathrm{b}$. The wear track of $\mathrm{W}_{95} \mathrm{~N}_{5}$ coating shows only shallow scratches parallel to the relative sliding movement. Defects in the wear tracks could be observed by SEM in the films with further increase of nitrogen content. The $\mathrm{W}_{90} \mathrm{~N}_{10}$ wear track is very similar to the previous one; however, cohesive failures of the coating could be detected. These failures contributed to the increase of the wear rate, since the wear debris contained large tungsten nitride particles causing abrasive wear due to their sharp edges and high hardness. The process of delamination of the large particles is clearly shown in Fig. 11.

$\mathrm{W}_{88} \mathrm{~N}_{12}$ sample exhibits the highest wear rate and friction coefficient. The number of delaminations in the wear track rapidly increases as well as the number of large $\mathrm{W}-\mathrm{N}$ particles, causing very deep scratches in the coating surface. The largest scratches are finished by the accumulation of coating material revealing plastic deformation, see Fig. 10b. The observation of the end of a typical scratch is depicted in Fig. 12. The growth mechanism of these defects is not clear, but it can be assumed that a large particle may get jammed in the coating surface causing a local increase of temperature, which enhances the tribo-oxidation of the coating. The tungsten oxides are much softer than the nitrides and, thus, local plastic deformation can occur. The EDX measurements revealed that the material in the defect is oxidized, which confirms this explanation. It should be pointed out, that the defects observed in the wear tracks of $\mathrm{W}_{88} \mathrm{~N}_{12}$ coating are the only oxidized parts of its wear track. This coating exhibits as well the lowest value of critical load $L_{\mathrm{c} 1}$, which can enhance the formation of large delaminated particles. Moreover, the ball wear scar is covered with deep scratches, thus, the delaminated particles are abrasive enough even to damage the ball surface.

The wear track of $\mathrm{W}_{85} \mathrm{~N}_{15}$ coating has shown more shallow scratches. No major defects of plastic deformations are visible in the wear track. As a consequence, compared to $\mathrm{W}_{88} \mathrm{~N}_{12}$ sample, the wear rate and the friction coefficient decrease significantly. This different behavior cannot be attributed to any change in the mechanical properties, since hardness, residual stress and critical load of both coatings are almost identical. However, as referred to above, the XRD analysis has revealed that from one coating to the other, the presence of the $\beta-\mathrm{W}_{2} \mathrm{~N}$ phase was detected which seems to affect the tribological behaviour. In fact, as presented in next section, the coatings with $\beta-\mathrm{W}_{2} \mathrm{~N}$ phase have similar wear mechanisms as $\mathrm{W}_{85} \mathrm{~N}_{15}$ one. 

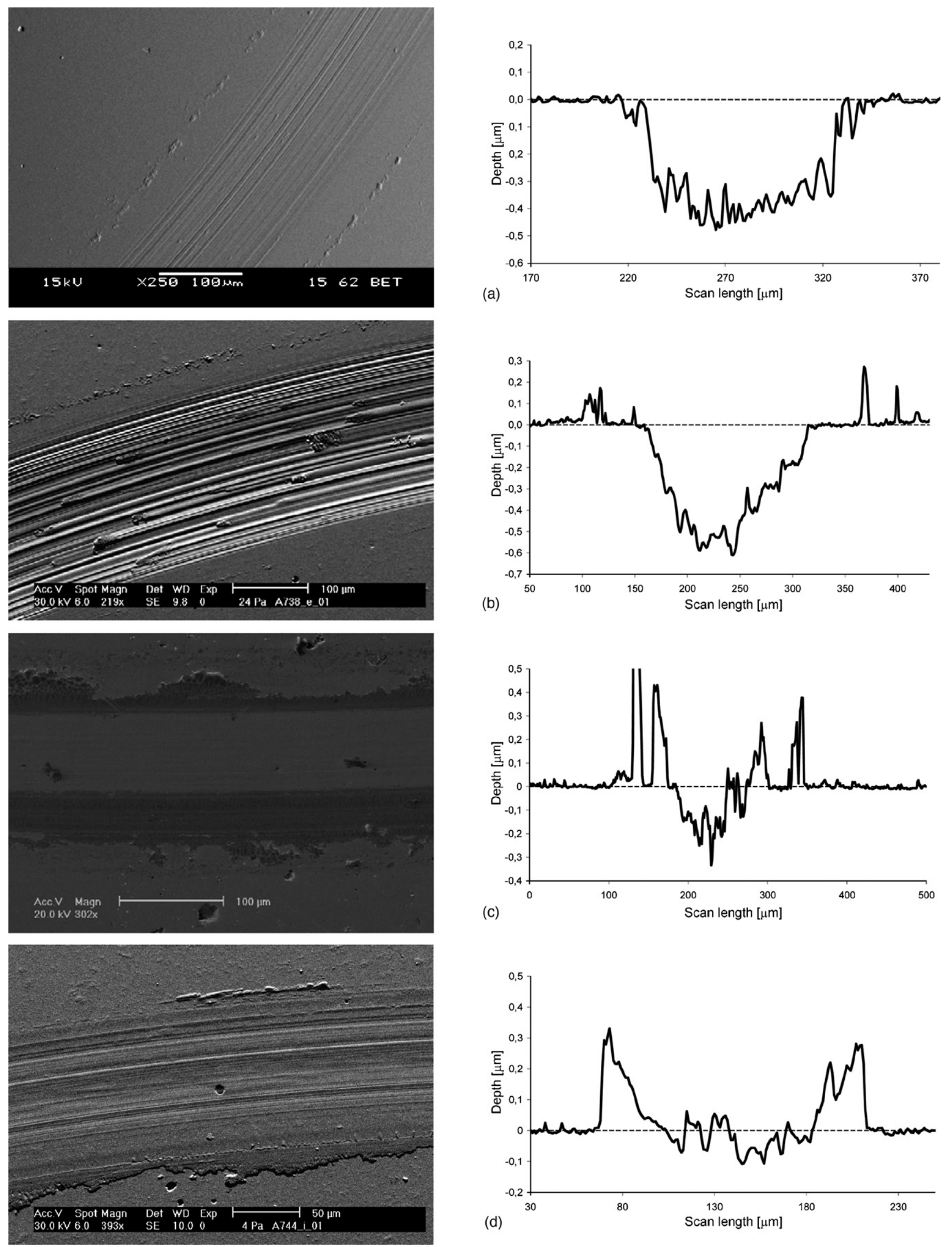

Fig. 10. SEM micrographs and corresponding profiles of the wear tracks for coatings with (a) $5 \%$, (b) $12 \%$, (c) $42 \%$ and (d) $55 \%$ of nitrogen content. Note the different scales in the plots. 


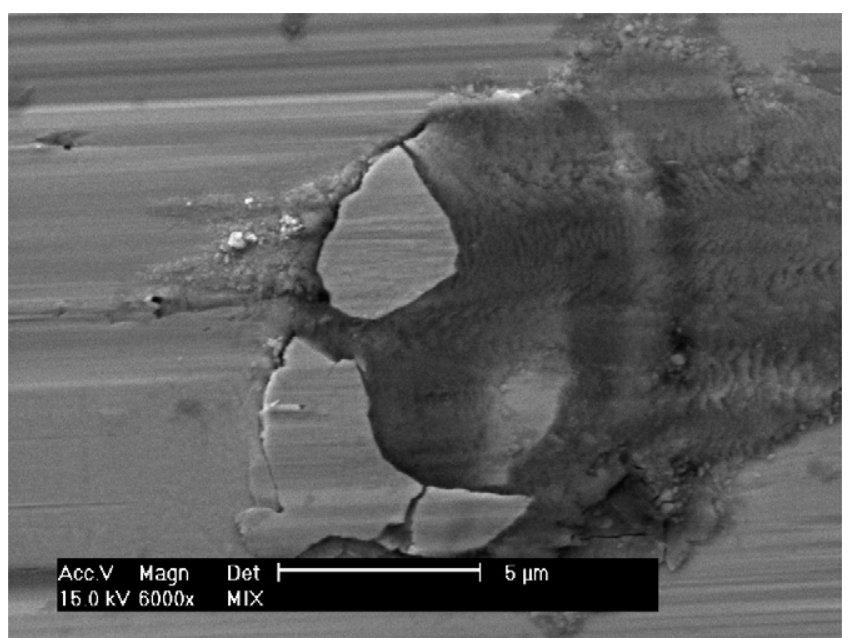

Fig. 11. SEM micrograph showing the formation process of the large particles, $\mathrm{W}_{90} \mathrm{~N}_{10}$ coating.

\section{2. $W-N$ coatings with high nitrogen content sliding against $\mathrm{Al}_{2} \mathrm{O}_{3}$ balls}

The wear debris produced during sliding of high- $\mathrm{N}$ content films against $\mathrm{Al}_{2} \mathrm{O}_{3}$ balls, is very homogenous containing only small round particles with grit size about 20-30 nm. Microanalysis of the wear debris has shown that their chemical composition is stoichiometric tungsten trioxide. The volume of adherent wear debris is much higher compared to that of low N-content coatings. The wear tracks are very smooth, neither defects nor cracks have been observed. The amount of wear debris accumulated on the sides of the wear track is very high (Fig. 10c and d) with a "negative" worn volume $(\mathrm{Sp})$ much larger than the positive one $(\mathrm{Sm})$. This behavior is well documented in Fig. 13 representing the $\mathrm{Sm} /(\mathrm{Sp}+\mathrm{Sm})$ ratio as a function of the nitrogen content. The large volume of wear debris, considerably exceeding the worn volume of the coating, can be easily explained by the difference in the density of the coatings and the adhered wear debris. The wear debris is exclusively stoichiometric tungsten triox-

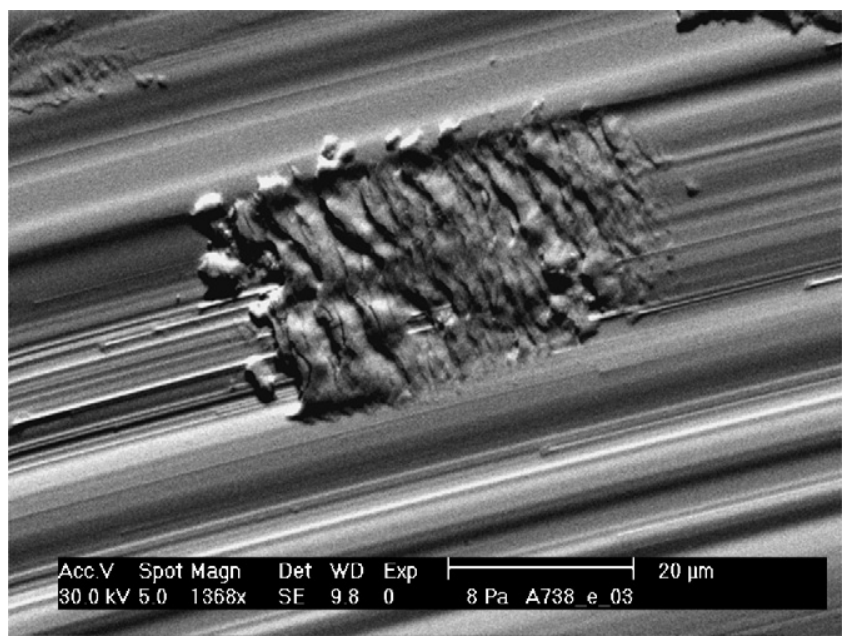

Fig. 12. The termination of a scratch observed in the wear track of $\mathrm{W}_{88} \mathrm{~N}_{12}$ coating. The relative movement of the ball is from the left to the right.

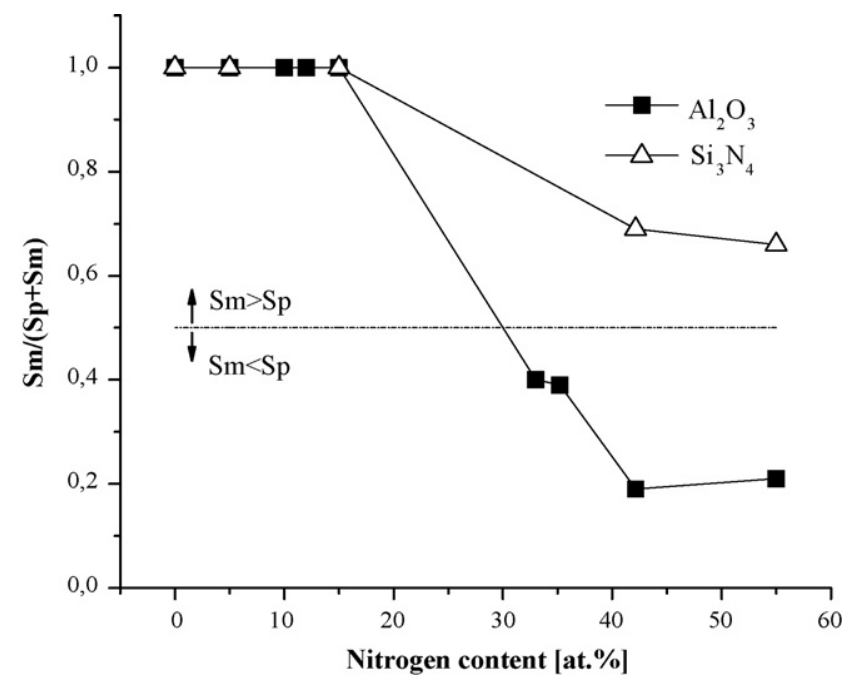

Fig. 13. $\mathrm{Sm} /(\mathrm{Sp}+\mathrm{Sm})$ ratio as a function of the nitrogen content. In case of $\mathrm{Al}_{2} \mathrm{O}_{3}$ balls, this ratio is lower than 0.5 for high $\mathrm{N}$-content, i.e. the "negative" coating worn volume is larger than the "positive" one.

ide, which is much less dense than bulk $\mathrm{WO}_{3}$ with a density of only $7.16 \mathrm{~g} \mathrm{~cm}^{-3}$ [22], when compared to $16.2 \mathrm{~g} \mathrm{~cm}^{-3}$ for the W-nitride calculated from XRD patterns (value indicated for $\beta-\mathrm{W}_{2} \mathrm{~N}$ phase [22]). In case of $\mathrm{W}_{45} \mathrm{~N}_{55}$ the wear debris cover almost all wear track. However, in the clean zones without wear debris, i.e. in the centre of the wear groove, the oxygen content is very low (Fig. 14) suggesting that no traces of oxidation of the coating is occurring on the contact surface.

\subsection{Wear mechanisms and wear modes of $W-N$ coatings sliding against $\mathrm{Al}_{2} \mathrm{O}_{3}$ balls}

A thorough characterization after tribological testing of coatings allows, in many cases, identifying the wear mechanisms

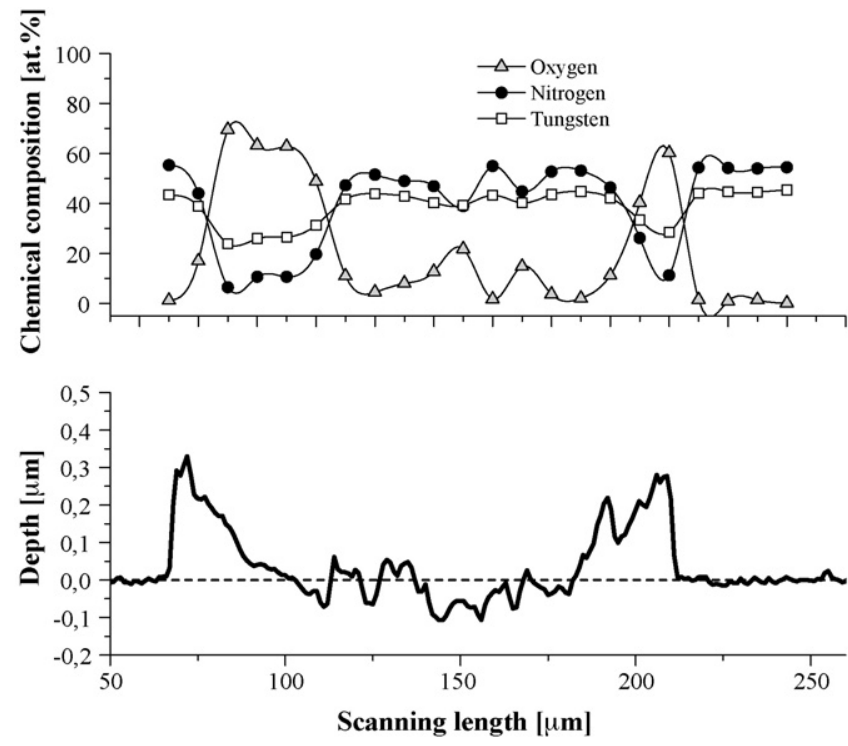

Fig. 14. Chemical composition across the wear track of $\mathrm{W}_{45} \mathrm{~N}_{55}$ coating sliding against $\mathrm{Al}_{2} \mathrm{O}_{3}$ ball measured by EPMA (above). The corresponding profile is shown below. 
that dominantly influence the wear behavior. However, for hard coatings it is not possible to find in the literature a complete standardization of the wear mechanisms and, consequently, the same results can be interpreted in a different way by several authors. Thus, in general in the present analysis, the basic definition of the wear mechanisms published in [15] and [23] will be followed. The wear modes, which are based on the appearance of worn surfaces, will be described in order to complement the information about the wear process.

For low nitrogen content films, the wear is driven by a combination of abrasion, delamination and tribo-oxidation. The influence of the interlayer of wear debris, which is forming between the surfaces in the contact, is negligible, since it does not adhere to any surface and is rapidly driven out from the contact area. Tribo-oxidation occurs during the entire test, since the majority of the wear debris particles are oxidized. The frictional heat generated by dry sliding, which is almost exclusively dissipated away through the asperities in contact, causes a significant local increase of temperature leading to the oxidation of each asperity [23]. Since the wear rate of $\mathrm{Al}_{2} \mathrm{O}_{3}$ balls is very low, the contact pressure remains very high due to the low contact area and $\mathrm{W}-\mathrm{N}$ film is more prone to oxidize. Thus, during the contact, as tungsten oxides have lower density than the nitrides, the asperities will oxidize and expand lifting apart the remaining asperities. This effect results in the concentration of both the frictional energy dissipation and the mechanical load on a few asperities only. The tungsten oxides are soft and the oxidized asperities can be plastically deformed and easily removed from the coating surface. This mechanism is typical for $\mathrm{W}_{95} \mathrm{~N}_{5}$ coating and can be described as a polishing and mild wear mode.

The delamination of large particles (Fig. 11) leads to tungsten-rich (i.e. not oxidized) particles in the wear debris for $\mathrm{W}_{90} \mathrm{~N}_{10}$ coatings (Fig. 9) revealing that other mechanism of material removal has to be considered. This coating exhibits the highest hardness, Young's modulus and, particularly, residual stress values. It is possible that the expansion of the oxidized asperities cannot be accommodated by the coating and, together with the stresses induced by the friction, creates cracks and enhances their propagation leading to coating chipping. The presence of hard sharp-edged particles in the contact is typical for abrasive wear, as it is confirmed by the presence of scratches in the wear track. The wear and friction coefficient increases as a result of the presence of the non-oxidized $\mathrm{W}-\mathrm{N}$ particles in the contact. Therefore, the abrasive process and delamination are the main wear mechanisms for $\mathrm{W}_{90} \mathrm{~N}_{10}$ film. These mechanisms are complemented by local plastic deformation in the case of $\mathrm{W}_{88} \mathrm{~N}_{12}$. As referred to above, the large particles can be embedded in the coating surface and be plastically deformed.

$\mathrm{W}_{85} \mathrm{~N}_{15}$ coating stands for the transition in the wear mechanism from low-N to high-N content films. In fact, in spite of having approximately the same mechanical properties $\left(H, E, L_{\mathrm{c}}\right.$, $\left.\sigma_{\mathrm{r}}\right)$ as $\mathrm{W}_{88} \mathrm{~N}_{12}$ film, its tribological behaviour starts to be different. Neither plastic deformation defects in the wear track nor $\mathrm{W}-\mathrm{N}$ particles in the wear debris were detected after the running test. The aspect of the wear track is only of polishing wear, resulting in a significant decrease of the friction coefficient and the wear rate. Moreover, for this film no adhered plates could be observed in the wear track.

The sliding of the coatings with high nitrogen content is typical of a three-body abrasive wear. In this case, the wear particles are free to slide over the surface, since they are not held rigidly. Consequently, the wear rate is much lower than for a two-body wear, characteristic of the low-N content films. The three-body wear is allowed by a rapid production of wear debris in the first stages of sliding. As discussed above, the tribo-oxidation of the contact asperities leads to an oxide layer on the coating surface. Nevertheless, how can the different wear mechanism be explained in relation to low-N content films? Would it be the higher production of wear debris for the coatings with high nitrogen content or the size of the formed oxide particles?

In previous work, the oxidation behaviour of pure tungsten and tungsten nitrides coatings prepared by magnetron sputtering has been studied [24]. It has been shown that the oxide layer on the tungsten coating is quite stable during the annealing, while sudden drops in the mass of the $\mathrm{N}$-containing specimen revealed the cracking and the consequent flaking off of the oxide layer at temperatures exceeding $650^{\circ} \mathrm{C}$. This behavior has been explained by the liberation of nitrogen, during the oxidation process of the nitride, which promoted the explosion and pulverization of the oxide layers. Thus, the removal of an oxidized material from the coating surface is enhanced by the liberated nitrogen and, if the size of the flaked particles is small enough, the rapid formation of a thick wear debris layer between the ball and the coating can occur. The thick interlayer between opposing surfaces is responsible of the increase of the contact area resulting in a decrease of the contact pressure. Consequently, the wear rate and the friction coefficient decrease. From an energetic point of view, the third-body absorbs a significant part of the heat induced by the friction, which is transformed in movement and deformation of the wear debris particles [23]. Moreover, the wear debris adheres on the sides of the wear track, where the contact pressure reaches minimal values. The surface of the central

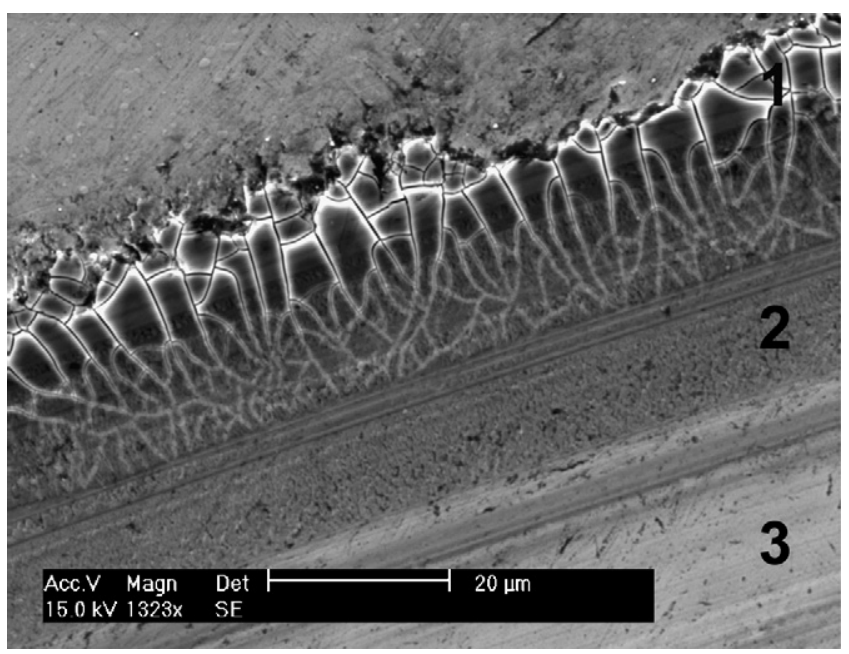

Fig. 15. Detail of the wear track of $\mathrm{W}_{45} \mathrm{~N}_{55}$ coating. 1, 2 - adhered wear debris consisting of tungsten trioxide, 3 - central groove exhibiting non-oxidized coating surface. 
groove of the wear track, which is neither covered by adhered oxide layer nor oxidized, is the only area of the coating material exposed to direct wear, since adhered oxide layers totally protect the coating surface (see Fig. 15). The adhered oxide layer on the sides of the wear track is very homogeneous. The cracks observed in Fig. 15 are the result of the residual stresses induced by the high contact pressure. In fact, these cracks are not visible after the tribological characterization and only appeared long time after the tests (the optical observations performed immediately after the tests revealed a smooth surface, while the SEM micrograph presented in Fig. 15 was taken 3 months later) and should not intervene in the sliding process.

The tribological behavior of a hard coating tested by pinon-disc is often explained by the dominant influence of one of the mechanical properties of the coatings. The improvement in the wear resistance is attributed to an increase of the hardness, the scratch-test resistance or the plasticity parameter $H^{3} / E^{2}$ among many others. Nevertheless, W-N coatings show a different behavior. Although the hardness, adhesion/cohesion or morphology may influence the friction coefficient or the wear rate of the coating, none of these properties can be considered as dominant. Moreover, coatings exhibiting similar mechanical properties can show very different tribological behavior. In this case, the type of wear mechanisms together with the presence of a wear debris interlayer forming a third-body play the dominant role in the tribological testing. In fact, the best wear resistance was achieved for the coatings with high $\mathrm{N}$-content exhibiting low hardness and low values of critical loads.

\section{4. $W-N$ coatings sliding against $\mathrm{Si}_{3} \mathrm{~N}_{4}$ balls}

The wear rate of $\mathrm{W}-\mathrm{N}$ coatings sliding against $\mathrm{Si}_{3} \mathrm{~N}_{4}$ balls shows a similar trend as the study with $\mathrm{A}_{2} \mathrm{O}_{3}$ counterparts, but with smaller values. Contrasting to the high $\mathrm{Si}_{3} \mathrm{~N}_{4}$ ball wear rates the amount of coating wear debris is very limited. The wear track on $\mathrm{W}_{95} \mathrm{~N}_{5}$ depicted in Fig. 16a is almost invisible in SEM micrograph, since the wear track is extremely smooth. The wear debris collected from this track consists of round particles of $\mathrm{WO}_{3}$, with an average grit size of $30 \mathrm{~nm}$, and smaller particles, probably silicon nitride and/or oxide. It should be remarked that due to the fact of the rapid wear of the $\mathrm{Si}_{3} \mathrm{~N}_{4}$ ball, the contact pressure decreases significantly making harder the tribo-oxidation of the W-N coating, explaining its lower wear rate when sliding against the $\mathrm{Si}_{3} \mathrm{~N}_{4}$ ball.

With increasing nitrogen contents, the wear tracks become rougher, due to a mixture of shallow scratches and accumulation

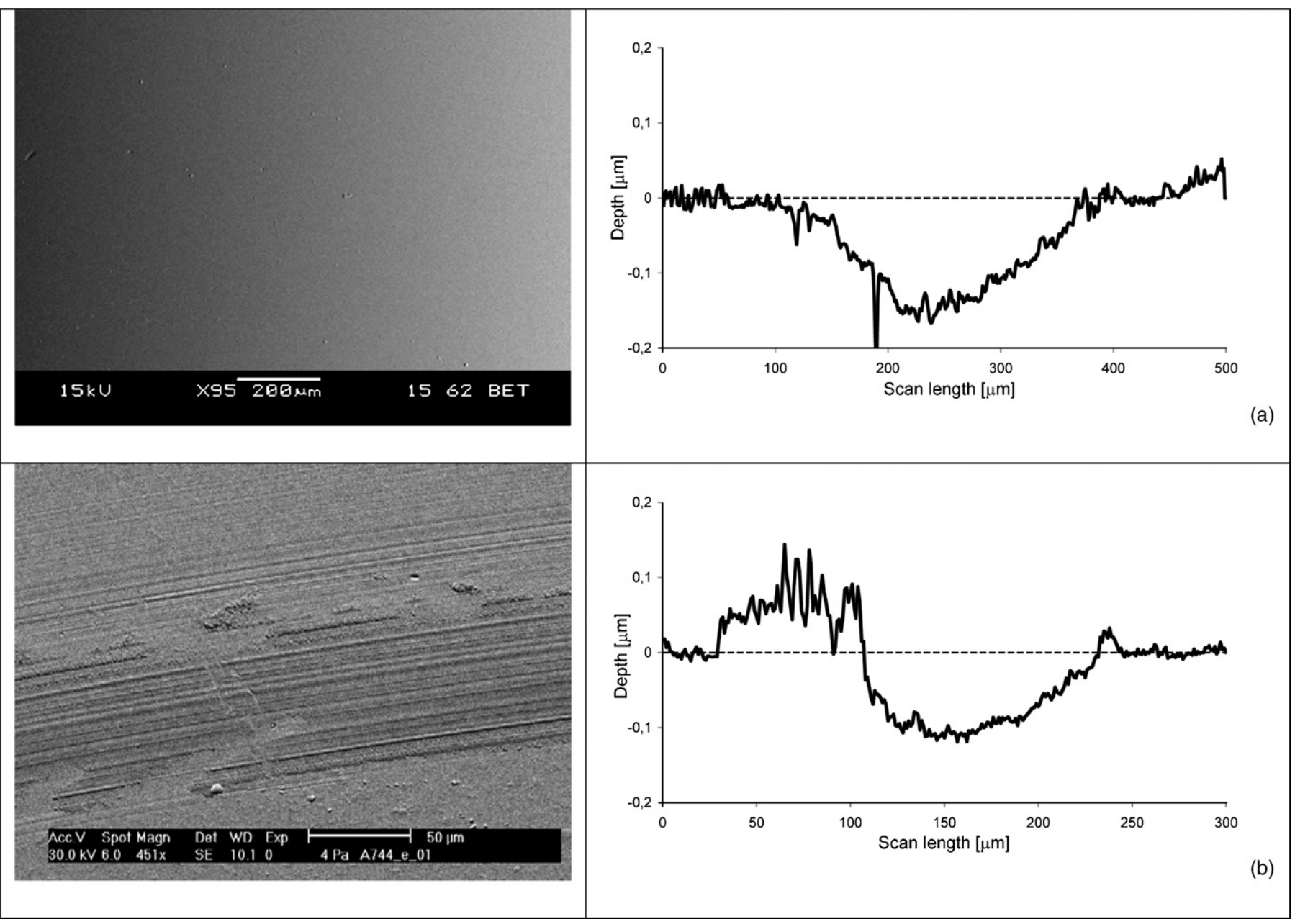

Fig. 16. SEM micrographs and profiles of the wear tracks for a $\mathrm{Si}_{3} \mathrm{~N}_{4}$ ball counterpart: (a) $\mathrm{W}_{95} \mathrm{~N}_{5}$, (b) $\mathrm{W}_{45} \mathrm{~N}_{55}$. 
of adherent wear debris as shown in Fig. 16b for the limiting case of $\mathrm{W}_{45} \mathrm{~N}_{55}$ film. Globally, the friction coefficients were a little higher than for $\mathrm{Al}_{2} \mathrm{O}_{3}$ counterparts, particularly for the higher $\mathrm{N}$ contents, probably due to the different constitution of the third-body layer. For $\mathrm{Al}_{2} \mathrm{O}_{3}$ it is formed almost exclusively of $\mathrm{WO}_{3}$, whereas for $\mathrm{Si}_{3} \mathrm{~N}_{4}$ a mixture of $\mathrm{WO}_{3}$ and $\mathrm{Si}-\mathrm{O} / \mathrm{N}$ is expected, since vestiges of silicon and nitrogen was identified in the EDX spectra of the wear debris. However, it is impossible to quantify silicon oxides and nitrides due to limitations of the $\mathrm{SEM} / \mathrm{EDX}$ for analysis of the wear particles with dimensions in nanometrical scale.

\section{Conclusions}

XRD analysis revealed that $\mathrm{W}-\mathrm{N}$ films can be deposited with different crystalline phases, $\alpha-\mathrm{W}, \beta-\mathrm{W}$ and $\beta-\mathrm{W}_{2} \mathrm{~N}$, as a function of increasing nitrogen content. All coatings showed compressive residual stress varying in the ranges from 3 to $5 \mathrm{GPa}$. Very high hardness values were reached, particularly for coatings exhibiting $\alpha-\mathrm{W}$ and $\beta-\mathrm{W}_{2} \mathrm{~N}$ phases (close to $40 \mathrm{GPa}$ ). As the coatings were deposited without substrate bias and adhesion interlayer, generally, low values of the critical loads were found when the coatings were submitted to scratch-testing. The wear of the tungsten nitride coatings can be tested only by $\mathrm{Al}_{2} \mathrm{O}_{3}$ and $\mathrm{Si}_{3} \mathrm{~N}_{4}$ balls; the $100 \mathrm{Cr} 6$ ball is not a suitable material due to the high wear resistance of the coatings. With the exception of tribo-oxidiation, present in all tested coated samples, the main wear mechanisms of low $\mathrm{N}$-content coatings were abrasive wear, delamination and, in the particular case of $\mathrm{W}_{88} \mathrm{~N}_{12}$ sample, plastic deformation. On the contrary, the sliding of the coatings with high nitrogen content was predominantly influenced by the formation of a third-body consisting of very small tungsten trioxide particles. Consequently, the main wear mechanism was three-body abrasive wear with combination with polishing and mild wear. The improvement of the wear resistance in case of high $\mathrm{N}$-content films was explained by the presence of the protecting interlayer between the opposing surfaces in contact.

The present study confirmed that either the wear process is a rather complex phenomena or it can be misguided to attribute the high wear resistance of hard coatings only to high hardness or scratch resistance. In fact, in this study, the best wear resistance was reached for coatings with the "worst" mechanical properties.

\section{Acknowledgements}

This work was supported by the European Union through the NMP3-CT-2003-505948 project "HARDECOAT". The authors would like to thank "Fundação para a Ciência e Tecnologia" of Portugal for the financial support through the POCI/V.5/A0034/2005 project "HARDECOAT - extension" and the SFRH/BD/16528/2004 Ph.D. Scholarship.

\section{References}

[1] L.E. Toth, Transition Metal Carbides and Nitrides, Academic Press, New York, 1971.

[2] M.-A. Nicolet, K. Affolter, H. Kattelus, Proc. Symp. Mat. Res. Soc. 47 (1985) 167

[3] P.J. Pokela, C.-K. Kwok, E. Kolawa, S. Raud, M.-A. Nicolet, Appl. Surf. Sci. 53 (1991) 364.

[4] L. Boukhris, J.-M. Poitevin, Thin Solid Films 310 (1997) 222.

[5] J. Castanho, A. Cavaleiro, M.T. Vieira, Vacuum 45 (1994) 1051.

[6] A. Cavaleiro, B. Trindade, M.T. Vieira, Surf. Coat. Technol. 174-175 (2003) 68

[7] C. Louro, A. Cavaleiro, Surf. Coat. Technol. 116-119 (1999) 74.

[8] Y.G. Shen, Y.W. Mai, d.R. Mackenzie, Q.C. Zhang, W.D. McFall, W.E. Bridge, J. Appl. Phys. 88 (2000) 1380.

[9] C.C. Baker, S.I. Shah, J. Vac. Sci. Technol. A 20 (5) 1699.

[10] S. Guruvenket, G.M. Rao, Mat. Sci. Eng. B106 (2004) 172.

[11] N.M.G. Parreira, N.J.M. Carvalho, A. Cavaleiro, Mater. Sci. Forum. 514-516 (2006) 825.

[12] J.M. Antunes, A. Cavaleiro, L.F. Menezes, M.I. Simões, J.V. Fernandes, Surf. Coat. Technol. 149 (2002) 27.

[13] G.G. Stoney, Proc. R. Soc. London A 82 (1909) 172.

[14] F. Vaz, L. Rebouta, P. Goudeau, J.P. Rivière, E. Schäffer, G. Kleer, M. Bodmann, Thin Solid Films 402 (2002) 195.

[15] K. Holmberg, A. Matthews, Coating Tribology, Elsevier, Amsterdam, 1994.

[16] N.M.G. Parreira, N.J.M. Carvalho, F. Vaz, A. Cavaleiro, Surf. Coat. Technol. 200 (2006) 6511.

[17] P. Villain, P. Goudeau, J. Ligot, S. Benayoun, K.F. Badawi, J.-J. Hantzpergue, J. Vac. Sci. Technol. A 21 (2003) 967.

[18] P. Petroff, T.T. Sheng, A.K. Sinha, G.A. Rozgonyi, F.B. Alevander, J. Appl. Phys. 44 (1973) 2545.

[19] S. Veprek, A.S. Argon, J. Vac. Sci. Technol. B 20 (2) (2002) 650.

[20] A. Leyland, A. Matthews, Wear 246 (2000) 1.

[21] J. Musil, F. Kunc, H. Zeman, H. Poláková, Surf. Coat. Technol. 154 (2002) 304.

[22] F. Mitsugi, E. Hiraiwa, T. Ikegami, K. Ebihara, R.K. Thareja, Jpn. J. Appl. Phys. 41 (2002) 5372.

[23] G.W. Stachowiak, W.B. Adrew, Engineering Tribology, ButterworthHeinemann, 2001

[24] C. Louro, A. Cavaleiro, Thin Solid Films 343-344 (1999) 51. 